\title{
Utilizing Mind Mapping to Summarize English Text with the Theme "American Culture"
}

\author{
Vivi Aulia \\ English Department, STKIP PGRI Banjarmasin \\ Email: viviauliavasa@yahoo.com
}

(Received: October-2017; Reviewed: November-2017; Accepted: December-2017; Published: December-2017)

\begin{abstract}
This research aims at knowing and describing on the utilization of mind mapping strategy in summarizing English text under the theme American Culture. It is conducted to the third semester of English Department students at STKIP PGRI Banjarmasin batch 2016 who take Reading III course. The instruments used in this research are observation sheet and documentation of students' mind map products. The observation sheet is analyzed qualitatively by describing the important result of observation process while the students' mind maps are analyzed quantitatively using mind mapping scoring rubric. They create mind mapping in post-reading activity. After reading, they have to summarize the text written through mind map. The result from the observation sheet shows that during four meetings of learning to create mind maps, students carry out the steps of creating mind map well. Although they get difficulties in early activities of this process, however, they can accomplish it well in the last meeting with a different topic of the text. Moreover, there are 17 (51\%) of 33 students as the subject of this research who have a good score on their mind maps products. It indicates that utilizing mind map is good enough for helping them to summarize the text written.
\end{abstract}

Keywords: utilizing; mind map; summarize; tex; American culture.

\section{INTRODUCTION}

Mastering English as a worldwide language to be used in communication becomes the requirement for those who want to challenge in the international job market. Further, mastery of English communication is the main requirement to be engaged in the world interaction. In the context of EFL teaching, we are required to master all English skills. Firstly, we need to have the ability for listening since we hear native speakers speak English and we should concern on it to have two ways communication. Secondly, we are required to master speaking skill actively to have daily communication with others. Next, for reading skill, we are trained to understand the content of English text to get meaningful comprehension. The last is in writing skill in which we learn to write down any kinds of writing activity properly.

One of the English skills that train us to use brain actively is reading skill. This is because reading needs highly cognitive process. Reading skill connects with the content of texts. The students or the learners who learn reading skill need the adequate comprehension of such text to get meaningful understanding. In other words, comprehension is a strategic process in which readers use cues from the 
text in conjunction with their existing knowledge to make predictions, monitor the predictions and construct meaning from the text (Klapwijk,2015:1). To get mastery in reading comprehension, such reading strategy is needed to facilitate students in learning reading.

Relating to the importance of providing such strategy in reading activity, however, we can help to improve students' comprehension through the instruction of reading strategies. Some review of related literatures show the use of possible strategy to facilitate students' comprehension. Gorlewski (2009:127-132), for instance, discussed on the use of comprehension reading strategies to improve reading skill. She reviews that making connections; questioning; visualizing and inferring; determining importance; and summarizing and synthesizing are some strategies that can be considered to help students' reading comprehension.

Among those strategies, summarizing is considered to be the difficult activity while the students comprehend the reading text. This is because during the summarizing process, the students should distinguish the main idea from the supporting ideas. Most of students have difficulties in doing this. Furthermore, they had difficulties in finding the content of English reading texts, especially the topic, main idea, and supporting ideas of the text. Such condition leads the researcher to an opinion that there might be an alternative strategy which can be applied in helping students to summarize the content of the reading text.

According to Kavishahi and Zafarghandi (2016:32), summarizing is reducing a text to the main points for a better understanding. This technique helps students to find out the essential ideas and consolidate critical information, which enables them to focus on keywords and phrases in a text. In addition, by summarizing, the students can comprehend the knowledge and transfer it to their long-term memory. This leads students to understand the text, distinguish main ideas, and express the information using their words. Moreover, summarizing help students to find out the essential ideas which enable them to focus on keywords.

As a way to help students summarize the text, mind mapping can be utilized to get meaningful comprehension. The mind map helps to organize the information in the text into a form that is easily assimilated and remembered. This way facilitates students to get general conclusion of thought so as to get the deep meaning of a text. Sabbah (2015:4) emphasizes that the learners transfer the text into a visual map to demonstrate the relationships among the text main ideas and its sub-ideas and to integrate the new information to his/her prior knowledge. Moreover, by utilizing mind map, we can plan, arrange, cluster, and even remember anything that has been known in advance so that it offers us to better recalling our memory.

This research focuses on the investigation of utilizing mind map to facilitate students to summarize the English text. Some studies have investigated this teaching strategy. First of all, Amine (2013:59-62) investigated the use of mind map technique to promote lesson summarizing in EFL instruction. He finds that the mind map technique can be implemented to students. Furthermore, the amount of information recalled from a given lesson can be increased by more than $61 \%$ by using mind map. It indicates that utilizing mind mapping is possible to be used for EFL instructional. Second, Sujana (2012:1-19) also examines the integration of mind mapping and information gap in teaching reading. The result shows that the mind mapping technique leads students to being active and creative in reading. It can be used to train their ability in finding out accurate information, note taking, and organizing ideas.

Based on the research finding that mind map strategy can be helpful for summarizing the text, the researcher is interested to investigate the use of mind mapping in reading activity. Therefore, a descriptive study on the use of this strategy is conducted on the third semester students batch 2016 taking Reading III course at the English Department of STKIP PGRI Banjarmasin.

STKIP PGRI Banjarmasin as one of the universities located in Banjarmasin has English department that trains and gives aid to the students to master English that will eventually prepare them to be professional English teachers. Within five semesters, they are trained on how to improve their reading skills (Reading I - V). The courses are designed to develop students' competence in literal, interpretive, affective, and critical reading within various texts, contexts, and genres. Since their first semester, the students are encouraged to 
understand English text through various teaching and learning activities.

Further, in the third semester, the teaching of reading (Reading III) is focused on how to increase the students' understanding and mastery toward English text focusing on complexity and difficulty of text, increasing their vocabulary mastery, developing and fostering their literal skills (i.e. knowing and comprehending). The students will be trained to be more active in reading aloud and emphasizing the use of appropriate reading strategies to identify the meaning. Beside that, the reading activity in the classroom mainly focus on the finding the topic and the main idea from supporting details of the texts as well as understanding explicit information from the text (Tim Pengembang Kurikulum STKIP PGRI Banjarmasin, 2012).

Due to the successful previous research of using mind map to summarize the text, the researcher would like to know and to examine its implementation in Reading III course. The objective of this research is describing on the use of it under the theme American Culture as the main discussion of reading text material.

\section{METHOD}

This research is conducted in Reading III course of English majors in STKIP PGRI Banjarmasin. The approach used is qualitative and quantitative. Qualitative approach intends to display the data in words and explanation while the quantitative one presents the data using number. This research uses descriptive method aiming at describes the utilization of mind mapping to summarize English text under the theme American Culture. The selection of American Culture as the theme of English text to be investigated is based on the consideration that the students will have additional knowledge and get positive values learning from American culture. Take for example, the value of discipline, the way of thinking, their lifestyles and eating habits, and others positive values from Western culture.

There are two classes engaged in this research. They are Morning class and Afternoon class. The total number of population is 33 students from those two classes and all of them are taken as subject of this research. Moreover, there are two instruments for collecting the data. They are observation sheet and documentation of students' product in creating the mind map. First of all, observation sheet is carried out to see and to observe the process of students creating mind map to summarize the text in each meeting of Reading III class. In this case, the students are asked to create mind map after discussing the text under the theme American Culture in the class. The researcher walks around the students' seat to monitor them one by one to make sure that each of them creates and produces the mind map actively. During this activity, the researcher takes notes and another important point that describes the process of how the students accomplish their mind maps.

The second instrument for collecting the data is documentation of students' mind map products. It refers to a collection of mind map product submitted by students after the whole reading text material have been discussed in the class. In other words, the students have to submit the collection of mind map based on the number of reading texts discussed in the classroom. There are four mind maps must be submitted by each of them. Every meeting discusses only one text and creates one mind map so that there are four meetings to finish all the texts. It represents the summary of four reading texts. The title of texts are "A Cultural Difference: Being on Time", "Changing Lifestyle and New Eating Habits", "Dreams: Making Them Work for Us", and "Language: Is It Always Spoken?" (Smith and Mare, 1994:368 ). The result of documentation of students' mind map products are assessed by using Mueller model of mind mapping scoring rubric as described by Coutinho (2014:116).

In details, the instructional activity in Reading III course to utilize mind map for summarizing the text is described as follows:

1. Distributing the reading text under the theme American Culture to students;

2. Asking the students to read and try to understand the content of the text individually;

3. Discussing the text with the whole class orally in which it discusses the implementation of some possible ways, such as: question-answer, group discussion, jigsaw, skimming, scanning, oral presentation, think pair share, SMART, and so on;

4. Asking the students to summarize the text individually by creating mind map based on 
the texts that have been discussed with the whole class;

5. If the class is over, asking the students to continue creating their mind maps at home. They are permitted to use colorful marker, providing relevant images, and others that support the content of their mind maps;

6. Asking the students to submit their mind maps product at the last meeting;

7. Scoring the students' mind maps to be assessed and checked whether appropriate or not with the content of the text;

8. Administering additional meeting to hold sharing of learning experiences in summarizing the text using mind map among the students.

The researcher analyzes the data obtained from the instruments. The result of observation sheet from students' activities is analyzed qualitatively. It records the factual information during the students' activities while they are creating their mind maps. The information recorded is in terms of explanation and detailed description of how mind mapping is utilized to summarize the text. The description covers the result and another supporting idea of it as well as other points that still need improvement in the future related to what should to consider in summarizing the reading text.

Meanwhile, the second instrument used for documentation of students' mind map products is analyzed quantitatively. Each of students' mind map products is assessed using mind map scoring rubric adapted from Mueller model. The final score of students' mind map products are matched with interval score as presented in Table 1 as follows:

Table 1 Interval Score of Students' Mind Map Products

\begin{tabular}{cc}
\hline Score & Level \\
\hline $71-80$ & Very good \\
\hline $51-70$ & Good \\
\hline $26-50$ & Fair \\
\hline $4-25$ & Poor \\
\hline
\end{tabular}

All the data from those instruments are considered to get the result and they are discussed in the following parts.

\section{FINDINGS AND DISCUSSION}

This part presents the result of data that have been collected and the discussion of those data based on the literature in the relevant field.

\section{Findings}

Findings of this research cover two areas. They are the result of observation sheets on the process of summarizing the text using mind map in each meeting and the result of students' final score in creating mind maps.

1. The result on the process of students utilizing mind map

In each meeting, it discusses reading text under the theme American Culture. First of all, in the first meeting, the reading class discussed the text entitle "A Cultural Difference: Being on Time". It talks about the difference between American culture and Brazilian culture in considering the lateness and the discipline custom. The researcher conducted question- answer activities and whole class discussion. In the end of reading activities, the students were asked to summarize the text individually through mind map. From this activity, the researcher found that 8 of 33 students (24\%) have difficulties in creating a mind map. They can summarize the text orally, however, reflecting the summary into the graphic organization of mind map is still confusing for them. As a result, the creation of their mind maps was still unclear.

Secondly, in the second meeting of reading class, the students discussed the next text entitled "Changing Lifestyle and New Eating Habits". This text discussed the way of life of American people on their eating habits. Furthermore, the text provides information on the food and beverage selection of American people to keep their health. The researcher conducted jigsaw activities in which the class is divided into groups. Some of them are grouped as initial group and others are grouped as expert group. Each group has a responsibility to learn the text, discuss, and help each other to understand the content of the text. When the jigsaw activity finished, the students were 
invited to summarize the text orally in turns. After that, they were asked to summarize the text written. The researcher found that they seemed to be familiar already with the form of mind maps. Some of them seemed to discuss with person next to them during the process of creating mind map, while some of others were actively arranged the keywords and images to be connected with hierarchical relationship based on the text.

Next, in the third meeting, the students discussed the text entitled "Dreams: Making Them Work for Us". It talks about the scientific heory of dream as phenomenon happen to human being. Moreover, this text gives an example on how American experts investigate and learn the positive impact of dream for us. Since this text is difficult enough to understand consisting some particular scientific terms, the researcher divided the class into groups. There are six paragraphs in this text. Each group was assigned to discuss the content of a paragraph so that six group discuss the whole content of it. After that, each group should present it in front of the class in turns. By doing this, the content of each paragraph can be learned and discussed together. In the end of the discussion, the students were asked to continue creating mind map based on the texts. Based on the observation carried out by the researcher, all the students can accomplish their mind maps well.

The last is discussing the fourth text entitled "Language: Is it Always Spoken?". This text mainly discusses the use of language orally and written for communication. The possibility of using sign language for certain people is also discussed in this text. The process of classroom discussion for this text is interactive enough. The students were enthusiastic in learning the information from the text. Based on the same strategy as previous meetings, the students were asked to create mind map based on the discussed text. The researcher has an expectation that in the last mind map, the students feel enjoy and can accomplish their summary through visual presentation better. There was no problem finishing the collection of their mind maps. The sample of the students' mind map products is presented in Figure 1, 2, and 3 as follows:

Figure 1. The Sample of Students' Mind Map Products for Text I

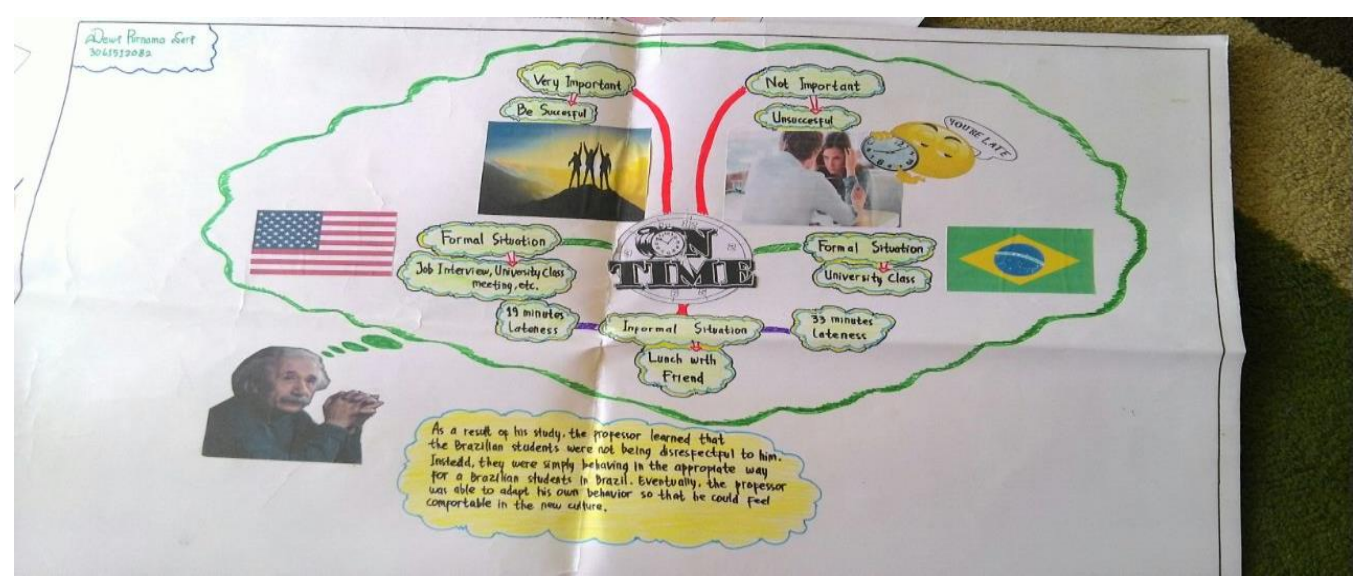

Figure 2. The Sample of Students' Mind Map Products for Text 2

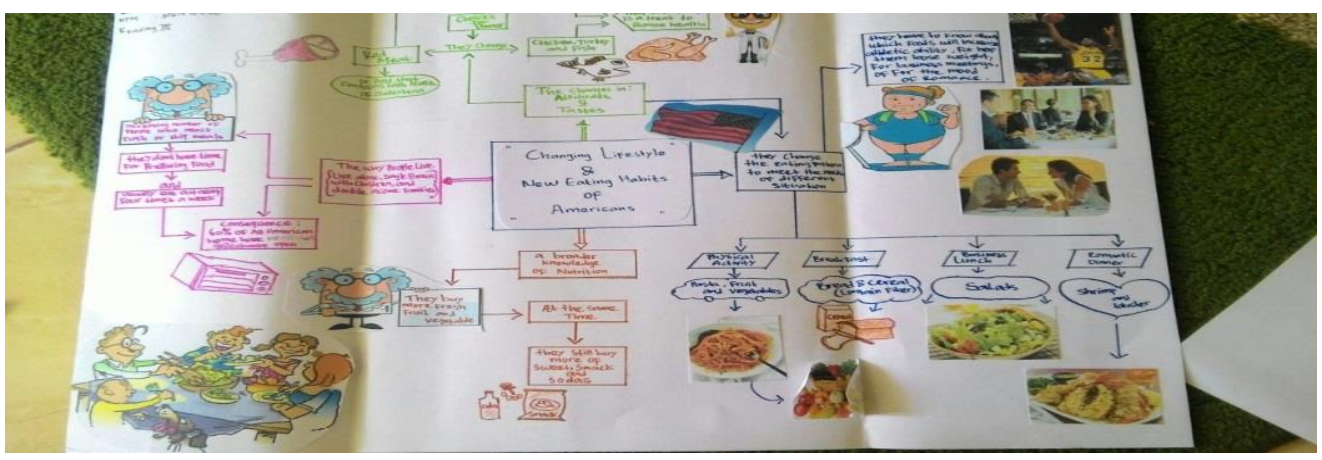




\section{Figure 3. The Sample of Students' Mind Map Products for Text 3}

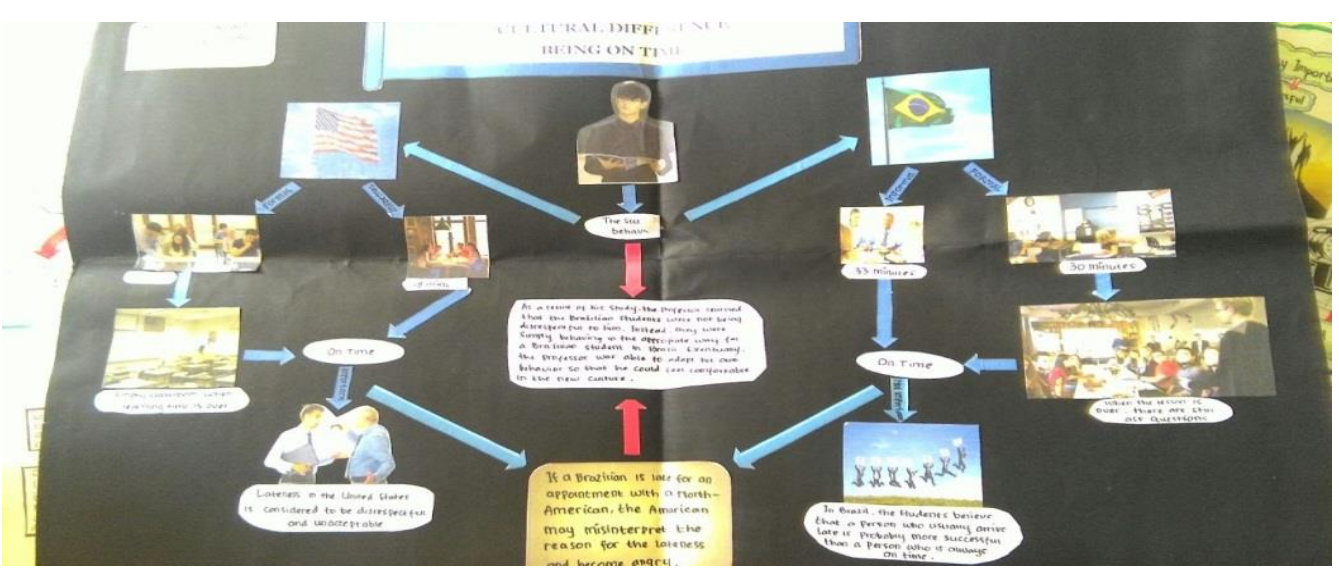

\section{The result of students' mind maps products}

The students' mind map products are evaluated and assessed by using mind mapping scoring rubric. The final result of students' mind maps scores is presented in Table 2.

Table 2. The Students' Final Scores of Mind Map Products

\begin{tabular}{ccccc}
\hline \multirow{2}{*}{ Mind Mapping } & \multicolumn{4}{c}{ The Percentage of Students' Scores } \\
\cline { 2 - 5 } & Very Good & Good & Fair & Poor \\
\hline Text 1 & $15 \%$ & $38 \%$ & $26 \%$ & $21 \%$ \\
\hline Text 2 & $23 \%$ & $52 \%$ & $15 \%$ & $10 \%$ \\
\hline Text 3 & $25 \%$ & $56 \%$ & $16 \%$ & $3 \%$ \\
\hline Text 4 & $37 \%$ & $58 \%$ & $5 \%$ & - \\
\hline Average & $\mathbf{2 5 \%}$ & $\mathbf{5 1 \%}$ & $\mathbf{1 6 \%}$ & $\mathbf{1 1 \%}$ \\
\hline $\begin{array}{c}\text { Total number of } \\
\text { students }\end{array}$ & $\mathbf{8}$ & $\mathbf{1 7}$ & $\mathbf{5}$ & $\mathbf{3}$ \\
\hline
\end{tabular}

Based on Table 2 above, it can be concluded that there are $51 \%$ of students who have enough good score. It indicates that most of them can apply the mind map as an alternative way to summarize the text. On the other hand, there are $16 \%$ as well as $11 \%$ of them who have bad scores due to the result that their mind map products are confusing. There is no relationship to keywords they write. The unity of concept that should be considered in creating mind map that tends to be ignored. As a result, someone who reads their works will have difficulty in understanding.

\section{Discussion}

Reading is a complex activity. It refers to the cognitive process in which the reader constructs meaning by understanding and interacting with the text. The success of reader interacts with such text to get meaningful comprehension depends on certain aspects.
Yang (2016:586) emphasizes that conceptual understanding, automated basic skills, and appropriate strategies are some key factors determining the success of a reader understand the text. Besides that, other factors that contribute to reader's ability gaining the content of the text is the text types and the reading situation.

Dealing with the complexity of reading comprehension, the readers should find out appropriate strategy to help them for it. Good reading strategy will lead us to get the content and important point stated in text easily. Effective strategy for reading can be applied in pre-reading activity, while reading, and even, is in post- reading activity. First of all, in prereading activity, we can try to preview; activate prior knowledge; and do anticipation guides, next, while reading covers skimming, scanning, inferencing, and identifying important information. The last is post-reading activity in 
which it can take the form of various activities, such as: discussing the text orally or written, summarizing orally or written, retelling what to read, making oral or written question, and thinking about how the text connects to one's own life.

One of important activities after reading the text is summarizing. It refers to activities in which a reader tries to underline important thing he/she got from the early until the end of text. An appropriate strategy to do this activity is creating mind map. According to Dixon and Lammi (2014:5), mind map is a cognitive strategy that leads a reader to summarize crucial information as well as to get better memorization toward the content of the text. It helps students to make connections to material in meaningful ways. By creating mind map, overall summary of certain text can be synthesized and identified through key ideas and relevant ideas. Better comprehension will be easily gained through written summary using mind map.

This study proves its utilization on students' reading activities. The result of this research shows that the students can perform well in summarizing the text written by utilizing mind mapping. The important point got from result of observation shows that the concept of creating mind map is easy enough to understand. Although the students get difficulties in the first meeting while they have to transfer the content of text into graphic organization, it is well done in the last meeting, otherwise. Mind mapping is helpful and beneficial to students in assisting them to comprehend a text. Significantly, it takes up the meaningful comprehension in postreading since more information, details, and examples stated in text can be clearly visualized.

Additionally, the result of students' mind map products also show that it is good enough in terms of their scores. There are $51 \%$ of students who have good scores for their works. Most of them can visualize the graphic connection between ideas successfully. Nevertheless, there are also many students who are still categorized getting fair and poor scores. Those who get these marks tend to create mind map without considering the unity of interrelationship both the organization of a text and the main ideas of that text. Thus, getting main idea of a text is one of the determinant factors which is very essential in comprehending reading text (Naidu et.al, 2013:60). In this case, the students seem to ignore this important part. Some of keywords do not connect with others. Hence, the result of their mind map products do not provide sufficient summary of the text clearly.

Among the good application of mind mapping for summarizing the text presented in this research, there is a technical weakness of mind mapping faced by students. With mind maps, everything is supposed to be visualized on a single page of paper. Sometimes, we need larger area to add something to that and there is no enough space on it. Unfortunately, if they create it in another page, it will disturb the idea association. Finally, the students should create rough draft in other papers so that they have fixed idea to be transferred into final mind map.

\section{CONCLUSION AND SUGGESTION}

This research has found out that the students perform better when creating the mind map to summarize the English text in postreading activity. In spite of having difficulties in the early process of creating the mind map, the students can accomplish it well at the end of these activities. Moreover, there are 17 of 33 students who have good scores on their mind map products. It means that utilizing mind map is useful enough for leading them summarize the text effectively.

Based on the result of this research, summarizing the text is one of important postreading activities to gain the students' brain in getting memorization of such text. It can be conducted through both oral and written. In general, oral summary is easy to do due to the fact that the students are able to express their ideas and to explain their comprehension of text using their own words. On the other hand, making written summary is different. It is cognitive process in which the students are required to have deep comprehension of certain text before being summarized. Finding out appropriate way to facilitate this cognitive process is recommended.

Mind mapping as a part of thinking process can be an alternative way to help students summarizing the text written. This research investigates the use of it and gets good results. Utilizing mind mapping to summarize the text is beneficial in transferring something implicitly stated in the text become explicitly clear to get the point. 
Due to the result of this research, possible suggestion is given to students who want to use this strategy. The number of circles and lines in mind map can provide them with much information about a text. However, they should follow the rules of creating mind map carefully so that their mind map products can be easily understood for those who read it.

\section{REFERENCES}

Amine, N.M. (2013). Introducing the mind map technique to promote lesson summarizing in EFL instruction. Published Dissertation. Biskra: Faculty of Letters and Languages Mohammed Kheider University

Coutinho, E. (2014). Concept maps: evaluation models for educators. Journal of Business and Management Sciences, 2(5):111-117

Dixon, R.A., and Lammi, M. (2014). Cognitive mapping technique: implications for research in engineering and technology education. Journal of Technology Education, 25(2):2-17

Gorlewski, J. (2009). Shouldn't they already know how to read? comprehension strategies in high school English. English Journal. 98(4):127-132.

Kavishahi, M.R. and Zafarghandi, A.M. (2016). The effect of mind mapping and summarizing on EFL reading comprehension ability. International
Journal of Language Learning and Applied Linguistic World (IJLLALW). 11(2):30-45

Klapwijk, N.M. (2015). $\mathrm{EMC}^{2}=$ comprehension. A reading strategy instruction framework for all teachers. South African Journal of Education, 35(1):1-10.

Naidu, B., Briewin, M., and Embi, M.A. (2013). Reading strategy: tackling reading through topic and main ideas. English Language Teaching, 6(11):60-64

Sabbah, S.S. (2015). The effect of college students' self-generated computerized mind mapping on their reading achievement. International Journal of Education and Development using Information and Communication Technology (IJEDICT). 11(3):4-36

Smith, L.C. and Mare, N.N. (1995). Issues for today. An intermediate reading skill text. Second Edition. Massachussets: Heinle and Heinle Publishers

Sujana, I.M. (2012). Integrating a mind mapping technique and information gap activities in teaching academic reading in English. English for Specific Purposes World, 36 (12): 1-19

Tim Pengembang Kurikulum STKIP PGRI Banjarmasin. (2012). Hasil lokakarya kurikulum 2012. Banjarmasin: STKIP PGRI Banjarmasin

Yang, X. (2016). Study on factors affecting learning strategies in reading comprehension. Journal of Language Teaching and Research, 7(3):586-590 